Review

\title{
Antithrombotic Strategies in Patients with Atrial Fibrillation and Acute Coronary Syndromes Undergoing Percutaneous Coronary Intervention
}

\author{
Leonardo De Luca 1,2,*(D), Raffaella Mistrulli ${ }^{3}$, Francesco Antonio Veneziano ${ }^{4}\left(\mathbb{D}\right.$, Francesco Grigioni ${ }^{4}$, \\ Massimo Volpe ${ }^{3}$, Francesco Musumeci ${ }^{1}$ and Domenico Gabrielli ${ }^{1}$
}

check for

updates

Citation: De Luca, L.; Mistrulli, R.; Veneziano, F.A.; Grigioni, F.; Volpe, M.; Musumeci, F.; Gabrielli, D. Antithrombotic Strategies in Patients with Atrial Fibrillation and Acute Coronary Syndromes Undergoing Percutaneous Coronary Intervention. J. Clin. Med. 2022, 11, 512. https:// doi.org/10.3390/jcm11030512

Academic Editors: Fabiana Lucà and Sandro Gelsomino

Received: 16 December 2021

Accepted: 17 January 2022

Published: 20 January 2022

Publisher's Note: MDPI stays neutral with regard to jurisdictional claims in published maps and institutional affiliations.

Copyright: (C) 2022 by the authors. Licensee MDPI, Basel, Switzerland. This article is an open access article distributed under the terms and conditions of the Creative Commons Attribution (CC BY) license (https:// creativecommons.org/licenses/by/ $4.0 /)$.
1 Department of Cardiosciences, A.O. San Camillo-Forlanini, 13449 Roma, Italy; fmusumeci@virgilio.it (F.M.); dgabrielli@scamilloforlanini.rm.it (D.G.)

2 UniCamillus-Saint Camillus International University of Health Sciences, 00131 Roma, Italy

3 Cardiology Department, Sapienza University of Rome, Sant'Andrea Hospital, 00185 Roma, Italy; mistrulliraffaella@gmail.it (R.M.); massimo.volpe@uniroma1.it (M.V.)

4 Unit of Cardiovascular Science, Department of Medicine, Campus Bio-Medico University, 00128 Roma, Italy; f.veneziano@unicampus.it (F.A.V.); f.grigioni@unicampus.it (F.G.)

* Correspondence: leo.deluca@libero.it or LDeLuca@scamilloforlanini.rm.it; Tel.: +39-06-58704419; Fax: +39-06-58704361

Abstract: Patients with atrial fibrillation (AF) are at increased risk for coronary artery disease (CAD). After percutaneous coronary intervention (PCI), the antithrombotic therapy consists of a combination of anticoagulant and antiplatelet agents to reduce the ischemic and thromboembolic risk, at the cost of increased bleeding events. In the past few years, several randomized clinical trials involving over 12,000 patients have been conducted to compare the safety of vitamin K antagonist (VKA) and direct-acting oral anticoagulants (DOACs) in association with a single- or double-antiplatelet agent, in the so-called dual- (DAT) or triple-antithrombotic therapy (TAT). These studies and several meta-analyses showed a consistent benefit for reducing bleeding events of DAT over TAT and of DOAC over VKA, without concerns about ischemic endpoints, except for a trend for increased stent thrombosis risk. The present paper examines current international guidelines' recommendations and reviews clinical trials, meta-analyses, and observational studies conducted on AF patients treated with DAT or TAT after PCI for acute coronary syndromes.

Keywords: atrial fibrillation; acute coronary syndrome; dual antithrombotic therapy; triple antithrombotic therapy

\section{Introduction}

The incidence of atrial fibrillation (AF), the most common sustained arrhythmia, is increasing as a consequence of the aging population and wide-spreading risk factors [1,2]. AF increases the risk of thromboembolic events and major cardiovascular adverse events, and it is one of the most common causes of death globally and a leading cause of disability [3-5].

Up to 2/5 of patients with AF present a concomitant coronary artery disease (CAD). Moreover, about $15 \%$ of patients with AF may require percutaneous coronary interventions (PCIs) with stent implantation to treat obstructive CAD [6]. After PCI, these patients would require an antithrombotic therapy combining oral anticoagulant (OAC) and antiplatelet agents, aimed to decrease both the risk of thromboembolism due to AF and the risk of acute ischemic events related to thrombosis of coronary stents $[7,8]$. The benefits of this strategy may be counterbalanced by the increasing risk of bleeding [9].

In order to prevent stroke, OAC has proven to be more efficient and safer than aspirin monotherapy and dual-antiplatelet therapy (DAPT) [9-12]. Conversely, with regard to the reductions of ischemic events post PCI (i.e., recurrent ischemic events and stent thrombosis (ST)), DAPT is the treatment of choice [13-16]. Patients with AF on triple-antithrombotic 
therapy (TAT) experience higher rates of major bleeding (e.g., bleeding requiring hospitalization or fatal bleeding) compared with patients on dual-antithrombotic therapy (DAT) or single-antiplatelet therapy (SAPT) [8]. Therefore, the optimal strategy for this group of patients has to weigh the precarious balance of ischemic and haemorrhagic risk [17].

To date, six randomized controlled trials (RCTs), including a total of 11,421 patients, have been published to respond to this need [18]. The most promising approach to reduce bleeding events appears to be represented by the choice of a direct anticoagulant agent (DOAC) rather than vitamin $\mathrm{K}$ antagonists (VKAs) and to reduce the length of TAT or to avoid it.

\section{Trials with VKAs}

In the What is the Optimal antiplatElet and anticoagulant therapy in patients with oral anticoagulation and coronary StenTing (WOEST) study [19], an open-label, randomized trial, 573 patients (28\% with ACS) receiving long-term therapy with warfarin (69\% because of AF), with an INR target of 2.0, were randomly assigned to receive clopidogrel alone $(n=284)$ or clopidogrel and aspirin $80 \mathrm{mg} /$ day $(n=289)$. The length of association treatment was one month after BMS placement and one year after DES placement $(65 \%$ of patients). During the 12 mo of follow-up, the primary endpoint of any TIMI bleedings was less frequent in patients receiving DAT than TAT (hazards ratio (HR) $0.36,95 \%$ CI $0.26-0.50, p<0.0001$ ), with no significant difference in TIMI major and GUSTO severe bleedings. Although it was not sufficiently powered for ischemic events, the rates of myocardial infarction (MI), stroke, target vessel revascularization, or ST did not significantly differ, but all-cause mortality at one year was lower in the dual-therapy group ( $2.5 \% \mathrm{vs}$. $6.4 \% ; p=0.027$, HR: 0.39, 95\% CI 0.16-0.93). Afterwards, in the Triple Therapy in Patients on Oral Anticoagulation After Drug Eluting Stent Implantation (ISAR TRIPLE) [20] trial, 614 patients ( $83 \%$ for $\mathrm{AF}$ or atrial flutter, $32 \%$ with ACS) were randomized to receive OAC for at least 12 mo and undergoing PCI with stent implantation (99\% DES) were randomized to TAT with clopidogrel for $6 \mathrm{wk}(n=307)$ vs. $6 \mathrm{mo}(n=307)$, on top of aspirin and $\mathrm{OAC}$, with the lowest recommended target international normalized ratio (INR) during the duration of TAT. At landmark analyses from $6 \mathrm{wk}$ to $9 \mathrm{mo}$, the primary endpoint (death, MI, definite ST, stroke, or TIMI major bleeding) did not differ between groups (9.8\% in the 6 wk group vs. $8.8 \%$ in the 6 mo group at 9 mo, HR: $1.14 ; 95 \%$ CI: 0.68 to $1.91 ; p=0.63$ ). No significant difference was registered in TIMI major bleeding (HR: 1.35 ; $95 \%$ CI: 0.64 to $2.84 ; p=0.44)$, even though in the $6 \mathrm{wk}$ group, there was a significantly lower risk of any Bleeding Academic Research Consortium (BARC) bleeding (HR: 0.68; 95\% CI: 0.47 to 0.98; $p=0.04)$. As WOEST, also ISAR-TRIPLE has limited power to detect ischemic endpoints.

\section{Trials with DOACs}

The OPen-Label, Randomized, Controlled, Multicenter Study ExplorIng TwO TreatmeNt StratEgiEs of Rivaroxaban and a Dose-Adjusted Oral Vitamin K Antagonist Treatment Strategy in Subjects with Atrial Fibrillation who Undergo Percutaneous Coronary Intervention (PIONEER) AF-PCI [21] was the first open-label randomized trial testing DAT with DOACs vs. TAT with VKAs. In this trial, 2124 non-valvular AF patients undergoing PCI with stenting $(66 \%$ DES, $40 \%$ with ACS) were randomized in a 1:1:1 ratio to receive: (1) rivaroxaban $15 \mathrm{mg}$ daily + P2Y12 inhibitors or (2) $1 \mathrm{mo}, 6 \mathrm{mo}$, or $12 \mathrm{mo}$ of DAPT plus rivaroxaban $2.5 \mathrm{mg}$ (twice daily, bid) followed by rivaroxaban $15 \mathrm{mg}$ daily + aspirin, or (3) $1 \mathrm{mo}, 6 \mathrm{mo}$, or $12 \mathrm{mo}$ of DAPT plus VKA followed by VKA plus aspirin (full TAT arm, with INR target of 2.0-3.0). The TAT duration was decided and prespecified by treating clinicians ( $1 \mathrm{mo}, 6 \mathrm{mo}$, or $12 \mathrm{mo}$ ). The P2Y12 inhibitor was mainly clopidogrel (93-96\%) and was continued up to one year in $49 \%$ of patients in the full TAT arm. The primary endpoint of clinically significant bleeding at 12 mo was reduced by both rivaroxaban-based strategies compared to the TAT group (for Group 1, HR 0.59, 95\% CI 0.47-0.76; $p<0.001$, and for Group 2, HR 0.63, 95\% CI 0.50-0.80; $p<0.001$ ) driven by lower rates of bleeding requiring medical attention, but not TIMI major or minor bleedings. The rivaroxaban-based 
regimen resulted in a reduced risk of total bleeding events and recurrent hospitalization for adverse events. The rate of major adverse cardiovascular events (a composite of death from cardiovascular causes, MI, or stroke) was similar in the three groups, as rates for each component of the endpoint, but also in this trial, the power for detecting differences in ischemic events was low.

Afterwards, in The open-label, Randomized Evaluation of Dual Antithrombotic Therapy with Dabigatran vs. Triple Therapy with Warfarin in Patients with Nonvalvular Atrial Fibrillation Undergoing Percutaneous Coronary Intervention (RE-DUAL PCI) [22] trial, 2725 patients with non-valvular AF, treated with intracoronary stenting $(66 \%$ DES, 40\% ACS), were randomized to (1) DOAC with dabigatran $110 \mathrm{mg}$ BID plus either clopidogrel or ticagrelor, (2) DOAC with dabigatran $150 \mathrm{mg}$ BID plus either clopidogrel or ticagrelor, or (3) TAT with warfarin plus aspirin ( $\leq 100 \mathrm{mg}$ daily) and either clopidogrel or ticagrelor. In the TAT group, aspirin was discontinued after 1 mo in the case of BMS and after 3 mo in the case of DES implantation. Ticagrelor was associated with dabigatran in $12 \%$ of patients. At $1 \mathrm{y}$, the incidence of the primary endpoint (first major or clinically relevant nonmajor bleeding event) was significantly lower in both dabigatran arms versus TAT group (HR: 0.52; 95\% CI, 0.42 to $0.63 ; p<0.001$ for noninferiority; $p<0.001$ for the superiority for the $110 \mathrm{mg}$ DAT group and HR, $0.72 ; 95 \%$ CI, 0.58 to $0.88 ; p<0.001$ for the noninferiority for $150 \mathrm{mg}$ the DAT group, respectively). The rates of major bleeding alone and total bleeding were significantly lower in both DAT groups than in the TAT group. There was no difference in the composite efficacy endpoint of thromboembolic events (MI, stroke, or systemic embolism), death, or unplanned revascularization among the DAT groups versus the TAT group (HR, 1.04; 95\% CI, 0.84 to $1.29 ; p=0.005$ for noninferiority). Interestingly, when $110 \mathrm{mg}$ BID dabigatran DAT was compared to TAT, there was a trend towards increased risk of MI (HR 1.51, 95\% CI 0.94-2.41, $p=0.09$ ) and definite ST (HR 1.86, 95\% CI 0.79-4.40, $p=0.15$ ); in contrast, there was no substantial difference between $150 \mathrm{mg}$ BID dabigatran DAT vs. TAT.

The largest study conducted to date in AF patients undergoing PCI is the AUGUSTUS (an open-label, $2 \times 2$ factorial, randomized controlled trial to evaluate the safety of apixaban vs. vitamin $\mathrm{K}$ antagonist and aspirin vs. placebo in patients with atrial fibrillation and acute coronary syndrome and/or percutaneous coronary intervention) [23]. It was a two-by-two factorial randomized trial that randomized 4614 patients with AF to apixaban $5 \mathrm{mg}$ BID versus VKAs (open-label) and aspirin versus placebo (blinded) on top of a P2Y12 inhibitor administered to all patients. Around $37 \%$ of patients presented with a PCI-treated ACS; $24 \%$ had medically managed ACS; $39 \%$ underwent elective PCI. All patients received a P2Y12 inhibitor, mainly clopidogrel (93\% of cases). The median time from the index event to randomization was $6 \mathrm{~d}$, while the TAT duration was 6 mo. At 6 mo, 10.5\% receiving apixaban had an ISTH major or clinically relevant nonmajor bleeding event, as compared to $14.7 \%$ receiving VKA (HR $0.69 ; 95 \%$ CI, 0.58 to $0.81 ; p<0.001$ for noninferiority; $p<0.001$ for superiority). Considering fatal and ischemic events, $23.5 \%$ who had been assigned to receive apixaban died or were hospitalized, as compared with $27.4 \%$ assigned to receive a VKA (HR 0.83; 95\% CI, 0.74 to $0.93 ; p=0.002$ ). Although also this trial was not powered to assess efficacy, in PCI-treated patients, there was a trend toward a two-fold increased risk of probable or definite ST and toward an increased rate of MI in the DAT versus TAT arm ischemic event.

In the antiplatelet regimen comparison, the primary outcome of major or clinically relevant nonmajor bleeding was significantly increased by aspirin compared with placebo (HR: $1.89 ; 95 \%$ CI: 1.59 to $2.24 ; p<0.001$ ). Patients in the aspirin group had a 6 mo incidence of death or hospitalization similar to the placebo group (HR 1.08; 95\% CI, 0.96 to 1.21). The incidence of death or hospitalization at 6 mo was higher among patients assigned to VKA and aspirin compared to those assigned to receive apixaban and placebo. Of note, nonsignificant $0.5 \%$ and $0.4 \%$ absolute increases in MI and ST, respectively, were noted in patients on placebo compared with those on aspirin. Therefore, AUGUSTUS helps to unravel the individual contribution of DOACs and aspirin withdrawal on the risk 
of bleeding. Importantly, compared with prior studies using DOACs, AUGUSTUS also included medically managed ACS patients, who are known to be at high ischemic risk.

Finally, the Edoxaban Treatment Versus Vitamin K Antagonist in Patients With Atrial Fibrillation Undergoing Percutaneous Coronary Intervention (ENTRUST-AF PCI) study [24] was the last trial using DOACs in this setting: 1506 patients (52\% with ACS) with AF undergoing PCI were assigned to edoxaban (60 mg once daily) plus a P2Y12 inhibitor (clopidogrel in $92 \%$ of cases) for 12 mo or a VKA in combination with a P2Y12 inhibitor and aspirin (100 mg once daily, for 1-12 mo, INR target 2.0-3.0). At $1 \mathrm{y}$, there were nonsignificant trends toward lower rates of the primary safety outcome (major or clinically relevant nonmajor bleeding) favouring DAT versus TAT (HR 0.83, 95\% CI 0.65-1.05; $p=0.001$ for noninferiority, margin hazards ratio 1.20; $p=0.11$ for superiority). Although even this latter trial was not powered to assess ischemic outcomes, the main efficacy outcome (the composite of cardiovascular death, stroke, systemic embolic events, MI, and definite ST) was similar between the two groups (HR for edoxaban 1.06 (95\% CI 0.71-1.69)). Interestingly, there was a very early numerical increase in ischaemic events in patients without aspirin, because of a nonsignificant trend toward increased risk of MI (HR 1.26, 95\% CI 0.72-2.16) and ST (HR $1.32,0.46-3.79$ ) (Table 1). 
Table 1. Design of major trials comparing TAT vs. DAT.

\begin{tabular}{|c|c|c|c|c|c|c|c|c|}
\hline & $\begin{array}{c}\text { Design, } \\
\text { Randomization }\end{array}$ & Patients ( $n$ ) & Treatment Arms & AF (\%) & $\begin{array}{l}\text { Maximum Days in } \\
\text { ASA in DAT Group }\end{array}$ & ACS (\%) & Follow Up (mo) & Primary Outcome \\
\hline WOEST & RCT open label, 1:1 & 573 & $\begin{array}{l}\text { VKA + P2Y12i for } 1 \text { or } 12 \text { mo vs. } \\
\text { VKA + aspirin + P2Y12i for } 1 \text { or } \\
12 \text { mo }\end{array}$ & 69 & $<1$ & 28 & 12 & $\begin{array}{l}\text { Any bleeding events (TIMI and } \\
\text { GUSTO criteria) }\end{array}$ \\
\hline ISAR-TRIPLE & RCT open label, 1:1 & 614 & $\begin{array}{l}6 \text { we of VKA + clopidogrel + } \\
\text { aspirin vs. } 6 \text { mo of VKA + } \\
\text { clopidogrel + aspirin }\end{array}$ & 84 & / & 32 & 9 & $\begin{array}{l}\text { A composite of death, MI, ST, } \\
\text { stroke, or major bleeding }\end{array}$ \\
\hline PIONEER-AF & RCT open label, 1:1:1 & 2124 & $\begin{array}{c}\text { rivaroxaban }(15 \mathrm{mg} / \mathrm{od})+\mathrm{P} 2 \mathrm{Y} 12 \mathrm{i} \\
\text { vs. rivaroxaban }(2.5 \mathrm{mg} / \mathrm{bid})+ \\
\text { aspirin }+\mathrm{P} 2 \mathrm{Y} 12 \mathrm{i} \text { vs. VKA }+ \\
\text { aspirin }+\mathrm{P} 2 \mathrm{Y} 12 \mathrm{i}\end{array}$ & 100 & 3 & 52 & 12 & $\begin{array}{c}\text { Clinically significant bleeding } \\
\text { (TIMI major, minor bleeding, or } \\
\text { bleeding requiring } \\
\text { medical attention) }\end{array}$ \\
\hline RE-DUAL PCI & RCT open label, 1:1:1 & 2725 & $\begin{array}{c}\text { dabigatran }(110 \mathrm{mg} / \mathrm{bid})+ \\
\text { P2Y12i vs. dabigatran }(150 \\
\mathrm{mg} / \mathrm{bid})+\mathrm{P} 2 \mathrm{Y} 12 \mathrm{i} \text { vs. VKA + } \\
\text { aspirin }(1-3 \text { months })+\mathrm{P} 2 \mathrm{Y} 12 \mathrm{i}\end{array}$ & 100 & 5 & 51 & 14 & $\begin{array}{l}\text { Clinically significant bleeding } \\
\text { (ISTH major bleeding or } \\
\text { clinically relevant nonmajor } \\
\text { bleeding event) }\end{array}$ \\
\hline AUGUSTUS & $\begin{array}{l}\text { RCT open label, } \\
2 \times 2\end{array}$ & 4614 & $\begin{array}{c}\text { apixaban }(5 \mathrm{mg} / \mathrm{bid})+\text { P2Y12i vs. } \\
\text { apixaban }(5 \mathrm{mg} / \mathrm{bid})+\text { aspirin }+ \\
\text { P2Y12i vs. VKA + P2Y12i vs. } \\
\text { VKA + aspirin + P2Y12 }\end{array}$ & 100 & 14 & 60 & 6 & $\begin{array}{l}\text { Clinically significant bleeding } \\
\text { (ISTH major or clinically } \\
\text { relevant nonmajor bleeding) }\end{array}$ \\
\hline
\end{tabular}

$\mathrm{RCT}$ = randomized controlled trial; MI = myocardial infarction; ST = stent thrombosis; ISTH = International Society on Thrombosis and Haemostasis; GUSTO = Global Utilization of Streptokinase and Tissue Plasminogen Activator for Occluded Coronary Arteries. 


\section{Current Recommendations}

\subsection{European Guidelines}

The 2020 European Society of Cardiology (ESC) guidelines on AF [4] recommend that in patients with AF and ACS undergoing an uncomplicated PCI, a TAT with aspirin, clopidogrel, and an OAC should be given during the peri-PCI period, up to $1 \mathrm{wk}$. Another option is to extend TAT up to $\leq 1$ mo when the risk of ST outweighs the bleeding risk [25] (class of recommendation IIa, level of evidence C). Regardless of the initial treatment plan, a DAT with OAC and an antiplatelet drug (preferably clopidogrel) is recommended for the first 12 mo after PCI for ACS [26,27] or 6 mo after PCI in patients with CCS (class of recommendation $\mathrm{I}$, level of evidence $\mathrm{A}$ ). Thereafter, OAC monotherapy is to be continued (irrespective of the stent type) [20]. In the absence of contraindications, a DOAC should be preferred to VKA in combination with antiplatelet therapy (class of recommendation I, level of evidence A) [28]. In patients with a high bleeding risk (HAS BLEED $\geq 3$ ), rivaroxaban $15 \mathrm{mg}$ OD should be considered instead of rivaroxaban $20 \mathrm{mg}$ OD or dabigatran $110 \mathrm{mg}$ BID should be preferred to dabigatran $150 \mathrm{mg}$ BID for the duration of concomitant antiplatelet therapy (class of recommendation IIa, level of evidence B) [21,29]. For patients with an indication for VKA in combination with antiplatelet therapy, the dose of VKA should be carefully monitored with an INR in the lower recommended range (2.0-2.5), and a good quality anticoagulation control, as reflected by high TTR (e.g., $>70 \%$ ). Notably, the use of ticagrelor or prasugrel as part of TAT is not recommended [30].

\subsection{North American Guidelines}

Updated guidelines and expert consensus documents in Europe and the United States are relatively aligned with respect to recommendations for antithrombotic therapy in patients with AF undergoing PCI [31]. The 2019 guidelines from American Heart Association/American College of Cardiology (AHA/ACC) suggest that patients with $\mathrm{AF}$ at increased risk of stroke (based on a $\mathrm{CHA}_{2}-\mathrm{DS}_{2}-\mathrm{VASc}$ risk score of two or greater) undergoing PCI with stenting normally require TAT. TAT should not go beyond a limited period of $4-6 \mathrm{wk}$, as this is the period of greatest risk of ST, especially in patients with ACS (class of recommendation $\mathrm{Ilb}$, level of evidence B-R). In this setting, it is recommended to choose clopidogrel instead of ticagrelor or prasugrel (class of recommendation IIa, level of evidence B-NR). An option is to use DAT with DOAC as an alternative to TAT to reduce bleeding [32,33] (class of recommendation IIa, level of evidence B-R). DAT is also recommended, instead of TAT, with VKA and clopidogrel or ticagrelor (class of recommendation IIa, level of evidence B-NR) [34,35].

\subsection{North American Consensus on Antithrombotic Therapy in Patients with AF Undergoing PCI}

In this consensus documents, the default strategy is to use OAC and DAPT in all patients with AF and who are treated with intracoronary stents, until hospital discharge [35]. After this period, it is recommended to withdraw aspirin, continuing DAT only. During the first month after PCI, there is an increased risk of thrombotic complications; therefore, it is reasonable to use TAT for one month in patients with high thrombotic risk and who have a reasonable low risk of bleeding. Anyway, it is not recommended to prolong TAT beyond one month after PCI [36,37]. Clopidogrel should be preferred as the P2Y12 inhibitor, but ticagrelor can be used in patients with high thrombotic risk and without high bleeding risk [38,39]. Accordingly, prasugrel should be avoided in patients concomitantly treated with an OAC. In patients who are eligible for a DOAC, this is preferred to VKA in combination with antiplatelet therapy. This recommendation stems from the consistent reduction in bleeding complications with a DOAC, including intracranial haemorrhage, without an apparent trade-off in efficacy [30]. The use of a lower dose is not recommended (with the exception of rivaroxaban $15 \mathrm{mg}$ since this has been studied in randomized trials) [23]. The duration of DAT depends on the patient's risk profile, and it may change from one year to six months after PCI in patients with high bleeding risk or low thrombotic 
risk. After this period, patients should discontinue antiplatelet therapy and receive OAT alone. Continuation of antiplatelet therapy as an adjunct to OAC beyond $1 \mathrm{y}$ should be reserved only for selected patients with a high risk for ischemic recurrences and low bleeding risk (Figure 1) [40].

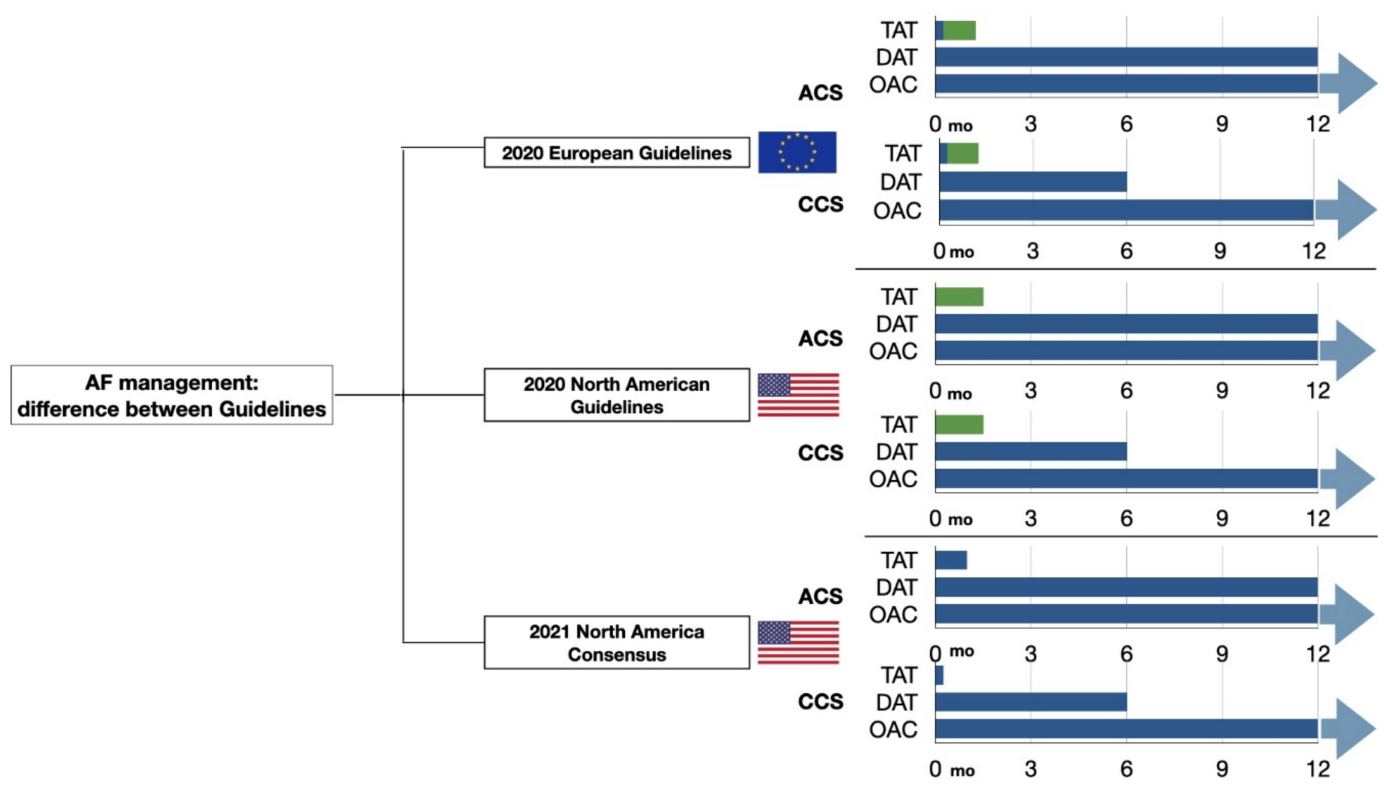

Figure 1. Antithrombotic therapy duration: differences across guidelines. ACS, acute coronary syndrome; AF, atrial fibrillation; CCS, chronic coronary syndrome; DAT, dual-antithrombotic therapy; OAC, oral anticoagulant; TAT, triple-antithrombotic therapy.

\subsection{European Heart Rhythm Association Practical Guide}

The recently published update of the European Heart Rhythm Association (EHRA) practical guide emphasises the concept that the choice of anticoagulant, as well as the duration of TAT, need to be personalized based on patient risk [41,42]. Notably, the assessment of bleeding risk should lead to correct reversible bleeding risk factors. Therefore, a careful follow-up can help to identify signs of occult bleeding. The treatment of patients undergoing an elective PCI is the same as for patients with ACS, but the transition to NOAC monotherapy should be made after six months instead of one year (Figure 2) [42].
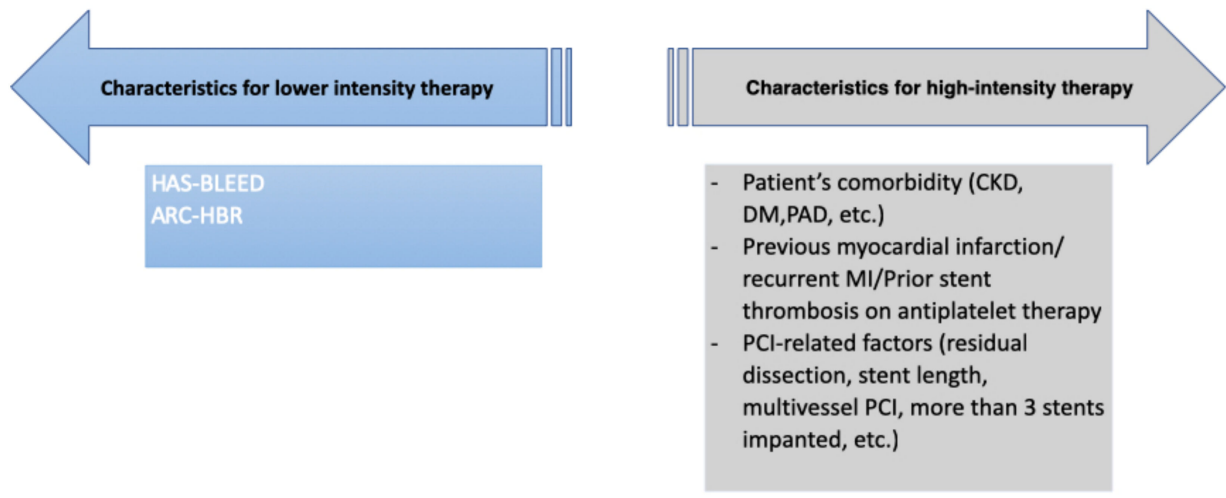

Figure 2. Risk factors associated with an increased risk of bleeding and an increased risk of ischemic coronary outcomes. ARB-HBR = The Academic Research Consortium for High Bleeding Risk; $\mathrm{CKD}=$ Chronic kidney disease; $\mathrm{DM}=$ Diabetes mellitus; PAD = Peripheral arterial disease; $\mathrm{MI}=$ Myocardial infarction; $\mathrm{PCI}=$ Percutaneous coronary intervention. 


\section{Metanalyses}

Following the publication of the dedicated randomized studies, fourteen metanalyses $[24,36,38,43-53]$ have been conducted, but only four analysed all four RCTs with DOACs. In all the aforementioned studies, DAT, compared to TAT, conferred a significantly reduced risk of overall bleeding. Although two metanalyses [24,49] reported comparable cardiovascular events (all-cause death, stroke, ST, or MI) with DAT vs. TAT with DOACs, others found a significant increase in ST with the use of DAT. Notably, the two meta-analyses not reporting increased ST rates with DAT did not use the definition recommended by the Academic Research Consortium 2, resulting in debatable results. In one of the most recent analyses [36], the odds of ST with DAT vs. TAT increased $60 \%$, with a number needed to harm of 274 and an associated borderline significant increase of MI. According to a subgroup pooled analysis [40] by the type of index event (ACS-related PCI vs. elective $\mathrm{PCI}$ ), the risk of MI resulted in being higher in patients with AF and ACS undergoing PCI and receiving an early DAT, as compared to TAT [18].

\section{Observational Studies}

The Register of Information and Knowledge about Swedish Heart Intensive care Admissions (RIKS-HIA) [54] analysed 6182 patients with AF and ACS admitted to the coronary care units of 72 Swedish hospitals from 1995 to 2002. The majority of patients enrolled presented $\mathrm{AF}$ at admission (78\%), while the remaining developed AF later (22\%). Among patients with AF, 29\% were prescribed a VKA alone or in association with aspirin (ASA), whereas $60 \%$ were given ASA and/or thienopyridine, and $11 \%$ did not receive any antiplatelet or anticoagulation therapy. Patients without any antithrombotic treatment had significantly higher 1 y mortality (45\%) than patients receiving platelet inhibitors only $(31 \%)$ or VKA (alone or in combination with platelet inhibitors; $22 \%$ ). OAC treatment was associated with a $29 \%$ relative and a $7 \%$ absolute reduction in 1 y mortality, mainly caused by a reduction in fatal stroke.

Another study investigated patients with AF admitted with MI or PCI between 2000 and 2009, using data from nationwide registries in Denmark [55]. The main aim was to evaluate the risk and time frame of bleeding associated with TAT in comparison with other treatment regimens. The cohort was divided into five groups based on the treatment regimen: SAPT with aspirin or clopidogrel; VKA monotherapy; DAPT; DAT or TAT using VKA. This study showed a net increase of bleeding immediately after initiation of TAT compared to other regimens, whereas the rate of the combined end points of cardiovascular death, MI, and ischemic stroke was similar for TAT and DAT.

The Management of Antithrombotic TherApy in Patients with Chronic or DevelOping AtRial Fibrillation During Hospitalization for PCI ( MATADOR-PCI ) was a prospective, observational, nationwide registry of ACS treated with PCI and concomitant AF conducted in Italy between August 2018 and December 2019. Five hundred ninety-eight consecutive patients were enrolled: $292(48.8 \%)$ with AF at hospital admission and 306 (51.2\%) developing AF during the index hospitalization. Among this latter group, 131 (42.8\%) developed AF before and 175 (57.2\%) after PCI. Among the 211 patients with AF at admission, 116 (55.0\%) had a permanent AF. DAPT, as the antithrombotic therapy at discharge, was prescribed in $26 \%$, TAT in $65 \%$, and DAT in $9 \%$ of patients. This latter strategy was mainly chosen for patients at high bleeding risk [56,57]. Clopidogrel was the most frequently used oral P2Y12 receptor inhibitor, while ticagrelor or prasugrel was prescribed in $2.3 \%$ and $13.5 \%$ of patients on TAT or DAT, respectively. DOACs were the most commonly used anticoagulant therapies both in patients receiving TAT or DAT. A low dosage of DOAC was employed in $71 \%$ of patients receiving TAT and $45 \%$ of those receiving DAT, but these prescriptions were appropriate only in $53 \%$ and $55 \%$ of patients receiving TAT or DAT, respectively [58]. Compared to the acute setting, the rate of TAT was significantly reduced (from $76.4 \%$ to $23.6 \%$ and from $53.8 \%$ to $23.6 \%$; both $p<0.0001$ ), while DAT was increased (from $11.8 \%$ to $56.3 \%$ and from $5.8 \%$ to $30.9 \%$; both $p<0.0001$ ) at 6 mo follow-up, in patients with pre-existing and new-onset $\mathrm{AF}$, respectively [59]. 


\section{Conclusions}

TAT exposes AF patients to a high bleeding risk at $30 \mathrm{~d}$ follow-up. Several randomized clinical trials involving approximately 12,000 patients demonstrated that DAT significantly reduces bleeding events compared to TAT. Current evidence suggests that DOAC, at the dose recommended for thromboembolic protection in $\mathrm{AF}$, should be preferred over VKA, while clopidogrel should be used when a TAT is prescribed. Further larger studies are needed to demonstrate if DAT might increase the risk of ST in certain subgroups of postPCI patients. International guidelines and consensus documents recommend DAT as the default strategy in AF patients $1 \mathrm{wk}$ after PCI, unless a high thrombotic and a low bleeding risk, needing TAT for a prolonged period of time, coexist. Observational studies suggest that TAT is still largely prescribed, while DAT is reserved for patients deemed at high bleeding risk. In this context, educational campaigns for the implementation of guideline recommendations are desirable.

Author Contributions: Conceptualization, L.D.L.; writing-original draft preparation, L.D.L., R.M. and F.A.V.; writing review and editing, L.D.L., R.M., F.A.V., F.G., M.V., F.M. and D.G. All authors have read and agreed to the published version of the manuscript.

Funding: This research received no external funding.

Conflicts of Interest: The authors declare no conflict of interest.

\section{References}

1. Wijesurendra, R.S.; Casadei, B. Mechanisms of atrial fibrillation. Heart 2019, 105, 1860-1867. [CrossRef] [PubMed]

2. Murphy, A.; Banerjee, A.; Breithardt, G.; Camm, A.J.; Commerford, P.; Freedman, B.; Gonzalez-Hermosillo, J.A.; Halperin, J.L.; Lau, C.P.; Perel, P.; et al. The World Heart Federation Roadmap for Nonvalvular Atrial Fibrillation. Glob. Heart 2017, 12, $273-284$. [CrossRef] [PubMed]

3. Campbell, B.; De Silva, D.A.; Macleod, M.R.; Coutts, S.B.; Schwamm, L.H.; Davis, S.M.; Donnan, G.A. Ischaemic stroke. Nat. Rev. Dis. Primers 2019, 5, 70. [CrossRef] [PubMed]

4. Hindricks, G.; Potpara, T.; Dagres, N.; Arbelo, E.; Bax, J.J.; Blomström-Lundqvist, C.; Boriani, G.; Castella, M.; Dan, G.A.; Dilaveris, P.E.; et al. 2020 ESC Guidelines for the diagnosis and management of atrial fibrillation developed in collaboration with the European Association for Cardio-Thoracic Surgery (EACTS): The Task Force for the diagnosis and management of atrial fibrillation of the European Society of Cardiology (ESC) Developed with the special contribution of the European Heart Rhythm Association (EHRA) of the ESC. Eur. Heart J. 2021, 42, 373-498.

5. January, C.T.; Wann, L.S.; Alpert, J.S.; Calkins, H.; Cigarroa, J.E.; Cleveland, J.C.; Conti, J.B., Jr.; Ellinor, P.T.; Ezekowitz, M.D.; Field, M.E.; et al. 2014 AHA/ACC/HRS guideline for the management of patients with atrial fibrillation: A report of the American College of Cardiology/American Heart Association Task Force on practice guidelines and the Heart Rhythm Society. Circulation 2014, 130, e199-e267. [CrossRef] [PubMed]

6. Capodanno, D.; Di Maio, M.; Greco, A.; Bhatt, D.L.; Gibson, C.M.; Goette, A.; Lopes, R.D.; Mehran, R.; Vranckx, P.; Angiolillo, D.J. Safety and Efficacy of Double Antithrombotic Therapy with Non-Vitamin K Antagonist Oral Anticoagulants in Patients with Atrial Fibrillation Undergoing Percutaneous Coronary Intervention: A Systematic Review and Meta-Analysis. J. Am. Heart Assoc. 2020, 9. [CrossRef]

7. Van Rein, N.; Heide-Jørgensen, U.; Lijfering, W.M.; Dekkers, O.M.; Sørensen, H.T.; Cannegieter, S.C. Major Bleeding Rates in Atrial Fibrillation Patients on Single, Dual, or Triple Antithrombotic Therapy. Circulation 2019, 139, 775-786. [CrossRef]

8. Stroke Prevention in Atrial Fibrillation Study. Final results. Circulation 1991, 84, 527-539.

9. Michniewicz, E.; Mlodawska, E.; Lopatowska, P.; Tomaszuk-Kazberuk, A.; Malyszko, J. Patients with atrial fibrillation and coronary artery disease-Double trouble. Adv. Med. Sci. 2018, 63, 30-35. [CrossRef]

10. ACTIVE Writing Group of the ACTIVE Investigators. Clopidogrel plus aspirin versus oral anticoagulation for atrial fibrillation in the Atrial fibrillation Clopidogrel Trial with Irbesart.tan for prevention of Vascular Events (ACTIVE W): A randomised controlled trial. Lancet 2006, 367, 1903-1912. [CrossRef]

11. Aguilar, M.I.; Hart, R.; Pearce, L.A. Oral anticoagulants versus antiplatelet therapy for preventing stroke in patients with nonvalvular atrial fibrillation and no history of stroke or transient ischemic attacks. Cochrane Database Syst. Rev. 2007, 3, CD006186. [CrossRef]

12. Ruiz-Nodar, J.M.; Marín, F.; Hurtado, J.A.; Valencia, J.; Pinar, E.; Pineda, J.; Gimeno, J.R.; Sogorb, F.; Valdés, M.; Lip, G.Y. Anticoagulant and antiplatelet therapy use in 426 patients with atrial fibrillation undergoing percutaneous coronary intervention and stent implantation implications for bleeding risk and prognosis. J. Am. Coll. Cardiol. 2008, 51, 818-825. [CrossRef]

13. Urban, P.; Macaya, C.; Rupprecht, H.J.; Kiemeneij, F.; Emanuelsson, H.; Fontanelli, A.; Pieper, M.; Wesseling, T.; Sagnard, L. Randomized evaluation of anticoagulation versus antiplatelet therapy after coronary stent implantation in high-risk patients: The multicenter aspirin and ticlopidine trial after intracoronary stenting (MATTIS). Circulation 1998, 98, 2126-2132. [CrossRef] 
14. Levine, G.N.; Bates, E.R.; Bittl, J.A.; Brindis, R.G.; Fihn, S.D.; Fleisher, L.A.; Granger, C.B.; Lange, R.A.; Mack, M.J.; Mauri, L.; et al. 2016 ACC/AHA Guideline Focused Update on Duration of Dual Antiplatelet Therapy in Patients With Coronary Artery Disease: A Report of the American College of Cardiology/American Heart Association Task Force on Clinical Practice Guidelines: An Update of the 2011 ACCF/AHA/SCAI Guideline for Percutaneous Coronary Intervention, 2011 ACCF/AHA Guideline for Coronary Artery Bypass Graft Surgery, 2012 ACC/AHA/ACP/AATS/PCNA/SCAI/STS Guideline for the Diagnosis and Management of Patients With Stable Ischemic Heart Disease, 2013 ACCF/AHA Guideline for the Management of ST-Elevation Myocardial Infarction, 2014 AHA/ACC Guideline for the Management of Patients With Non-ST-Elevation Acute Coronary Syndromes, and 2014 ACC/AHA Guideline on Perioperative Cardiovascular Evaluation and Management of Patients Undergoing Noncardiac Surgery. Circulation 2016, 134, e123-e155.

15. Capodanno, D.; Alfonso, F.; Levine, G.N.; Valgimigli, M.; Angiolillo, D.J. ACC/AHA Versus ESC Guidelines on Dual Antiplatelet Therapy: JACC Guideline Comparison. J Am Coll. Cardiol. 2018, 72, 2915-2931. [CrossRef] [PubMed]

16. Valgimigli, M.; Bueno, H.; Byrne, R.A.; Collet, J.P.; Costa, F.; Jeppsson, A.; Jüni, P.; Kastrati, A.; Kolh, P.; Mauri, L.; et al. 2017 ESC focused update on dual antiplatelet therapy in coronary artery disease developed in collaboration with EACTS: The Task Force for dual antiplatelet therapy in coronary artery disease of the European Society of Cardiology (ESC) and of the European Association for Cardio-Thoracic Surgery (EACTS). Eur. Heart J. 2018, 39, 213-260. [PubMed]

17. Lucà, F.; Giubilato, S.; Fusco, S.; Leone, A.; Poli, S.; Rao, C.M.; Iorio, A.; Gelsomino, S.; Gabrielli, D.; Colivicchi, F.; et al. The Combination of Oral Anticoagulant and Antiplatelet Therapies: Stay One Step Ahead. J Cardiovasc. Pharmacol. Ther. 2020, 25, 391-398. [CrossRef] [PubMed]

18. Galli, M.; Andreotti, F.; D’Amario, D.; Vergallo, R.; Montone, R.A.; Niccoli, G.; Crea, F. Randomised trials and meta-analyses of double vs triple antitrombotic therapy fo.or atrial fibrillation-ACS/PCI: A critical appraisal. Int. J. Cardiol. Heart Vasc. 2020, 28,100524

19. Dewilde, W.J.; Oirbans, T.; Verheugt, F.W.; Kelder, J.C.; De Smet, B.J.; Herrman, J.P.; Adriaenssens, T.; Vrolix, M.; Heestermans, A.A.; Vis, M.M.; et al. Use of clopidogrel with or without aspirin in patients taking oral anticoagulant therapy and undergoing percutaneous coronary intervention: An open-label, randomised, controlled trial. Lancet 2013, 381, 1107-1115. [CrossRef]

20. Fiedler, K.A.; Maeng, M.; Mehilli, J.; Schulz-Schüpke, S.; Byrne, R.A.; Sibbing, D.; Hoppmann, P.; Schneider, S.; Fusaro, M.; Ott, I.; et al. Duration of Triple Therapy in Patients Requiring Oral Anticoagulation After Drug-Eluting Stent Implantation: The ISAR-TRIPLE Trial. J. Am. Coll. Cardiol. 2015, 65, 1619-1629. [CrossRef]

21. Gibson, C.M.; Mehran, R.; Bode, C.; Halperin, J.; Verheugt, F.; Wildgoose, P.; van Eickels, M.; Lip, G.Y.; Cohen, M.; Husted, S.; et al . An open-label, randomized, controlled, multicenter study exploring two treatment strategies of rivaroxaban and a dose-adjusted oral vitamin $\mathrm{K}$ antagonist treatment strategy in subjects with atrial fibrillation who undergo percutaneous coronary intervention (PIONEER AF-PCI). Am. Heart J. 2015, 169, 472-478.e5.

22. Cannon, C.P.; Bhatt, D.L.; Oldgren, J.; Lip, G.; Ellis, S.G.; Kimura, T.; Maeng, M.; Merkely, B.; Zeymer, U.; Gropper, S.; et al. Dual Antithrombotic Therapy with Dabigatran after PCI in Atrial Fibrillation. N. Engl. J. Med. 2017, 377, 1513-1524. [CrossRef] [PubMed]

23. Lopes, R.D.; Heizer, G.; Aronson, R.; Vora, A.N.; Massaro, T.; Mehran, R.; Goodman, S.G.; Windecker, S.; Darius, H.; Li, J.; et al. Antithrombotic Therapy after Acute Coronary Syndrome or PCI in Atrial Fibrillation. N. Engl. J. Med. 2019, 380, 1509-1524. [CrossRef]

24. Vranckx, P.; Valgimigli, M.; Eckardt, L.; Tijssen, J.; Lewalter, T.; Gargiulo, G.; Batushkin, V.; Campo, G.; Lysak, Z.; Vakaliuk, I.; et al. Edoxaban-based versus vitamin $\mathrm{K}$ antagonist-based antithrombotic regimen after successful coronary stenting in patients with atrial fibrillation (ENTRUST-AF PCI): A randomised, open-label, phase 3b trial. Lancet 2019, 394, 1335-1343. [CrossRef]

25. Paciaroni, M.; Agnelli, G.; Micheli, S.; Caso, V. Efficacy and safety of anticoagulant treatment in acute cardioembolic stroke: A meta-analysis of randomized controlled trials. Stroke 2007, 38, 423-430. [CrossRef] [PubMed]

26. Steffel, J.; Verhamme, P.; Potpara, T.S.; Albaladejo, P.; Antz, M.; Desteghe, L.; Haeusler, K.G.; Oldgren, J.; Reinecke, H.; RoldanSchilling, V.; et al. The 2018 European Heart Rhythm Association Practical Guide on the use of non-vitamin K antagonist oral anticoagulants in patients with atrial fibrillation. Eur. Heart J. 2018, 39, 1330-1393. [CrossRef] [PubMed]

27. Saxena, R.; Lewis, S.; Berge, E.; Sandercock, P.A.; Koudstaal, P.J. Risk of early death and recurrent stroke and effect of heparin in 3169 patients with acute ischemic stroke and atrial fibrillation in the International Stroke Trial. Stroke 2001, 32, $2333-2337$. [CrossRef]

28. Yasuda, S.; Kaikita, K.; Akao, M.; Ako, J.; Matoba, T.; Nakamura, M.; Miyauchi, K.; Hagiwara, N.; Kimura, K.; Hirayama, A.; et al. Antithrombotic Therapy for Atrial Fibrillation with Stable Coronary Disease. N. Engl. J. Med. 2019, 381, 1103-1113. [CrossRef]

29. Lopes, R.D.; Hong, H.; Harskamp, R.E.; Bhatt, D.L.; Mehran, R.; Cannon, C.P.; Granger, C.B.; Verheugt, F.; Li, J.; Berg, J.M.T.; et al. Optimal Antithrombotic Regimens for Patients With Atrial Fibrillation Undergoing Percutaneous Coronary Intervention: An Updated Network Meta-analysis. JAMA Cardiol. 2020, 5, 582-589. [CrossRef] 
30. Lip, G.; Collet, J.P.; Haude, M.; Byrne, R.; Chung, E.H.; Fauchier, L.; Halvorsen, S.; Lau, D.; Lopez-Cabanillas, N.; Lettino, M.; et al. 2018 Joint European consensus document on the management of antithrombotic therapy in atrial fibrillation patients presenting with acute coronary syndrome and/or undergoing percutaneous cardiovascular interventions: A joint consensus document of the European Heart Rhythm Association (EHRA), European Society of Cardiology Working Group on Thrombosis, European Association of Percutaneous Cardiovascular Interventions (EAPCI), and European Association of Acute Cardiac Care (ACCA) endorsed by the Heart Rhythm Society (HRS), Asia-Pacific Heart Rhythm Society (APHRS), Latin America Heart Rhythm Society (LAHRS), and Cardiac Arrhythmia Society of Southern Africa (CASSA). Europace 2019, 21, 192-193.

31. January, C.T.; Wann, L.S.; Calkins, H.; Chen, L.Y.; Cigarroa, J.E.; Cleveland, J.C.; Ellinor, P.T., Jr.; Ezekowitz, M.D.; Field, M.E.; Furie, K.L.; et al. 2019 AHA/ACC/HRS Focused Update of the 2014 AHA/ACC/HRS Guideline for the Management of Patients With Atrial Fibrillation: A Report of the American College of Cardiology/American Heart Association Task Force on Clinical Practice Guidelines and the Heart Rhythm Society in Collaboration With the Society of Thoracic Surgeons. Circulation 2019, 140, e125-e151.

32. Sarafoff, N.; Martischnig, A.; Wealer, J.; Mayer, K.; Mehilli, J.; Sibbing, D.; Kastrati, A. Triple therapy with aspirin, prasugrel, and vitamin $\mathrm{K}$ antagonists in patients with drug-eluting stent implantation and an indication for oral anticoagulation. J. Am. Coll. Cardiol. 2013, 61, 2060-2066. [CrossRef] [PubMed]

33. Jackson, L.R.; Ju, C.; Zettler, M.; Messenger, J.C.; Cohen, D.J.; Stone, G.W.; Baker, B.A.; Effron, M.; Peterson, E.D.; Wang, T.Y. Outcomes of Patients With Acute Myocardial Infarction Undergoing Percutaneous Coronary Intervention Receiving an Oral Anticoagulant and Dual Antiplatelet Therapy: A Comparison of Clopidogrel Versus Prasugrel From the TRANSLATE-ACS Study. JACC Cardiovasc. Interv. 2015, 8, 1880-1889. [CrossRef] [PubMed]

34. Lamberts, M.; Gislason, G.H.; Olesen, J.B.; Kristensen, S.L.; Olsen, A.M.S.; Mikkelsen, A.; Christensen, C.B.; Lip, G.Y.; Køber, L.; Torp-Pedersen, C.; et al. Oral anticoagulation and antiplatelets in atrial fibrillation patients after myocardial infarction and coronary intervention. J. Am. Coll. Cardiol. 2013, 62, 981-989. [CrossRef] [PubMed]

35. Braun, O.Ö.; Bico, B.; Chaudhry, U.; Wagner, H.; Koul, S.; Tydén, P.; Scherstén, F.; Jovinge, S.; Svensson, P.J.; Smith, J.G.; et al. Concomitant use of warfarin and ticagrelor as an alternative to triple antithrombotic therapy after an acute coronary syndrome. Thromb. Res. 2015, 135, 26-30. [CrossRef]

36. Angiolillo, D.J.; Bhatt, D.L.; Cannon, C.P.; Eikelboom, J.W.; Gibson, C.M.; Goodman, S.G.; Granger, C.B.; Holmes, D.R.; Lopes, R.D.; Mehran, R.; et al. Antithrombotic Therapy in Patients With Atrial Fibrillation Treated With Oral Anticoagulation Undergoing Percutaneous Coronary Intervention: A North American Perspective: 2021 Update. Circulation 2021, 143, 583-596. [CrossRef] [PubMed]

37. Gargiulo, G.; Goette, A.; Tijssen, J.; Eckardt, L.; Lewalter, T.; Vranckx, P.; Valgimigli, M. Safety and efficacy outcomes of double vs. triple antithrombotic therapy in patients with atrial fibrillation following percutaneous coronary intervention: A systematic review and meta-analysis of non-vitamin $\mathrm{K}$ antagonist oral anticoagulant-based randomized clinical trials. Eur. Heart J. 2019, 40, 3757-3767.

38. Galli, M.; Andreotti, F.; Porto, I.; Crea, F. Intracranial haemorrhages vs. stent thromboses with direct oral anticoagulant plus single antiplatelet agent or triple antithrombotic therapy: A meta-analysis of randomized trials in atrial fibrillation and percutaneous coronary intervention/acute coronary syndrome patients. Europace 2020, 22, 538-546.

39. Orme, R.C.; Parker, W.; Thomas, M.R.; Judge, H.M.; Baster, K.; Sumaya, W.; Morgan, K.P.; McMellon, H.C.; Richardson, J.D.; Grech, E.D.; et al. Study of Two Dose Regimens of Ticagrelor Compared with Clopidogrel in Patients Undergoing Percutaneous Coronary Intervention for Stable Coronary Artery Disease (STEEL-PCI). Circulation 2018, 138, 1290-1300. [CrossRef]

40. Franchi, F.; Rollini, F.; Been, L.; Briceno, M.; Maaliki, N.; Wali, M.; Rivas, A.; Pineda, A.M.; Suryadevara, S.; Soffer, D.; et al. Pharmacodynamic and Pharmacokinetic Effects of a Low Maintenance Dose Ticagrelor Regimen Versus Standard Dose Clopidogrel in Diabetes Mellitus Patients Without Previous Major Cardiovascular Events Undergoing Elective Percutaneous Coronary Intervention: The OPTIMUS-6 Study. Circulation 2020, 142, 1500-1502.

41. Steffel, J.; Collins, R.; Antz, M.; Cornu, P.; Desteghe, L.; Haeusler, K.G.; Oldgren, J.; Reinecke, H.; Roldan-Schilling, V.; Rowell, N.; et al. 2021 European Heart Rhythm Association Practical Guide on the Use of Non-Vitamin K Antagonist Oral Anticoagulants in Patients with Atrial Fibrillation. Europace 2021, 23, 1612-1676. [CrossRef]

42. Collet, J.P.; Thiele, H.; Barbato, E.; Barthélémy, O.; Bauersachs, J.; Bhatt, D.L.; Dendale, P.; Dorobantu, M.; Edvardsen, T.; Folliguet, T.; et al. 2020 ESC Guidelines for the management of acute coronary syndromes in patients presenting without persistent ST-segment elevation. Eur. Heart J. 2021, 42, 1289-1367. [CrossRef] [PubMed]

43. Potpara, T.S.; Mujovic, N.; Proietti, M.; Dagres, N.; Hindricks, G.; Collet, J.P.; Valgimigli, M.; Heidbuchel, H.; Lip, G. Revisiting the effects of omitting aspirin in combined antithrombotic therapies for atrial fibrillation and acute coronary syndromes or percutaneous coronary interventions: Meta-analysis of pooled data from the PIONEER AF-PCI, RE-DUAL PCI, and AUGUSTUS trials. Europace 2020, 22, 33-46.

44. Galli, M.; Andreotti, F.; D'Amario, D.; Vergallo, R.; Montone, R.A.; Porto, I.; Crea, F. Dual therapy with direct oral anticoagulants significantly increases the risk of stent thrombosis compared to triple therapy. Eur. Heart J. Cardiovasc. Pharm. 2020, 6, 128-129. [CrossRef]

45. Haller, P.M.; Sulzgruber, P.; Kaufmann, C.; Geelhoed, B.; Tamargo, J.; Wassmann, S.; Schnabel, R.B.; Westermann, D.; Huber, K.; Niessner, A.; et al. Bleeding and ischaemic outcomes in patients treated with dual or triple antithrombotic therapy: Systematic review and meta-analysis. Eur. Heart J. Cardiovasc. Pharm. 2019, 5, 226-236. [CrossRef] 
46. Andò, G.; Costa, F. Double or triple antithrombotic therapy after coronary stenting and atrial fibrillation: A systematic review and meta-analysis of randomized clinical trials. Int. J. Cardiol. 2020, 302, 95-102. [CrossRef] [PubMed]

47. Khan, S.U.; Osman, M.; Khan, M.U.; Khan, M.S.; Zhao, D.; Mamas, M.A.; Savji, N.; Al-Abdouh, A.; Hasan, R.K.; Michos, E.D. Dual Versus Triple Therapy for Atrial Fibrillation After Percutaneous Coronary Intervention: A Systematic Review and Meta-analysis. Ann. Intern. Med. 2020, 172, 474-483. [CrossRef] [PubMed]

48. Golwala, H.B.; Cannon, C.P.; Steg, P.G.; Doros, G.; Qamar, A.; Ellis, S.G.; Oldgren, J.; Berg, J.M.T.; Kimura, T.; Hohnloser, S.H.; et al. Safety and efficacy of dual vs. triple antithrombotic therapy in patients with atrial fibrillation following percutaneous coronary intervention: A systematic review and meta-analysis of randomized clinical trials. Eur. Heart J. 2018, 39, 1726-1735a. [CrossRef]

49. Lopes, R.D.; Hong, H.; Harskamp, R.E.; Bhatt, D.L.; Mehran, R.; Cannon, C.P.; Granger, C.B.; Verheugt, F.; Li, J.; Berg, J.M.T.; et al. Safety and Efficacy of Antithrombotic Strategies in Patients With Atrial Fibrillation Undergoing Percutaneous Coronary Intervention: A Network Meta-analysis of Randomized Controlled Trials. JAMA Cardiol. 2019, 4, 747-755. [CrossRef]

50. Cavallari, I.; Patti, G. Meta-Analysis Comparing the Safety and Efficacy of Dual Versus Triple Antithrombotic Therapy in Patients with Atrial Fibrillation Undergoing Percutaneous Coronary Intervention. Am. J. Cardiol. 2018, 121, 718-724. [CrossRef] [PubMed]

51. Kheiri, B.; Osman, M.; Bakhit, A.; Radaideh, Q.; Abdalla, A.; Barbarawi, M.; Zayed, Y.; Ahmed, S.; Bachuwa, G.; Hassan, M. Dual versus triple therapy for patients with atrial fibrillation and acute coronary syndrome: A meta-analysis and trial sequential analysis of randomized controlled trials. J. Thromb. Thrombolysis 2019, 48, 511-513. [CrossRef]

52. Brunetti, N.D.; Tarantino, N.; De Gennaro, L.; Correale, M.; Santoro, F.; Di Biase, M. Direct oral anticoagulants versus standard triple therapy in atrial fibrillation and PCI: Meta-analysis. Open Heart 2018, 5, e000785. [CrossRef]

53. Piccini, J.P.; Jones, W.S. Triple Therapy for Atrial Fibrillation after PCI. N. Engl. J. Med. 2017, 377, 1580-1582. [CrossRef]

54. Stenestrand, U.; Lindbäck, J.; Wallentin, L.; RIKS-HIARegistr. Anticoagulation therapy in atrial fibrillation in combination with acute myocardial infarction influences long-term outcome: A prospective cohort study from the Register of Information and Knowledge About Swedish Heart Intensive Care Admissions (RIKS-HIA). Circulation 2005, 112, 3225-3231. [CrossRef]

55. Lamberts, M.; Olesen, J.B.; Ruwald, M.H.; Hansen, C.M.; Karasoy, D.; Kristensen, S.L.; Køber, L.; Torp-Pedersen, C.; Gislason, G.H.; Hansen, M.L. Bleeding after initiation of multiple antithrombotic drugs, including triple therapy, in atrial fibrillation patients following myocardial infarction and coronary intervention: A nationwide cohort study. Circulation 2012, 126, 1185-1193. [CrossRef]

56. De Luca, L.; Rubboli, A.; Bolognese, L.; Gonzini, L.; Urbinati, S.; Murrone, A.; di Uccio, F.S.; Ferrari, F.; Lucà, F.; Caldarola, P.; et al. Antithrombotic management of patients with acute coronary syndrome and atrial fibrillation undergoing coronary stenting: A prospective, observational, nationwide study. BMJ Open 2020, 10, e041044. [CrossRef]

57. De Luca, L.; Rubboli, A.; Bolognese, L.; Uguccioni, M.; Lucci, D.; Blengino, S.; Campodonico, J.; Meynet, I.; Prever, S.M.B.; Di Lenarda, A.; et al. Is percutaneous coronary intervention safe during uninterrupted direct oral anticoagulant therapy in patients with atrial fibrillation and acute coronary syndromes? Open Heart 2021, 8, e001677. [CrossRef] [PubMed]

58. De Luca, L.; Bolognese, L.; Rubboli, A.; Vetrano, A.; Callerame, M.; Rivetti, L.; Gonzini, L.; Gabrielli, D.; Di Lenarda, A.; Gulizia, M.M.; et al. Combinations of antithrombotic therapies prescribed after percutaneous coronary intervention in patients with acute coronary syndromes and atrial fibrillation: Data from the nationwide MATADOR-PCI registry. Eur. Heart J. Cardiovasc. Pharm. 2021, 7, e45-e47. [CrossRef] [PubMed]

59. De Luca, L.; Di Lenarda, A.; Rubboli, A.; Bolognese, L.; Gonzini, L.; Fortuni, F.; Navazio, A.; Poletti, F.; Ledda, A.; Urbinati, S.; et al. Post-discharge antithrombotic management and clinical outcomes of patients with new-onset or pre-existing atrial fibrillation and acute coronary syndromes undergoing coronary stenting: Follow-up data of the MATADOR-PCI study. Eur. J. Intern. Med. 2021, 88, 28-34. [CrossRef] [PubMed] 